\title{
Eat or Throw Away? Factors Differentiating High Food Wasters from Low Food Wasters
}

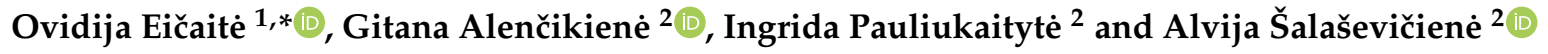 \\ 1 Lithuanian Centre for Social Sciences, Institute of Economics and Rural Development, A. Vivulskio Str. 4A-13, \\ LT 03220 Vilnius, Lithuania \\ 2 Food Institute, Kaunas University of Technology, Radvilènu Str. 19C, LT 50254 Kaunas, Lithuania; \\ gitana.alencikiene@ktu.lt (G.A.); ingrida.pauliukaityte@ktu.edu (I.P.); alvija.salaseviciene@ktu.lt (A.Š.) \\ * Correspondence: ovidija.eicaite@laei.lt
}

Citation: Eičaitè, O.; Alenčikienè, G.; Pauliukaitytè, I.; Šalaševičienè, A.

Eat or Throw Away? Factors

Differentiating High Food Wasters from Low Food Wasters. Sustainability 2021, 13, 10741. https://doi.org/ $10.3390 /$ su131910741

Academic Editor:

Piergiuseppe Morone

Received: 25 August 2021

Accepted: 23 September 2021

Published: 27 September 2021

Publisher's Note: MDPI stays neutral with regard to jurisdictional claims in published maps and institutional affiliations.

Copyright: (C) 2021 by the authors. Licensee MDPI, Basel, Switzerland. This article is an open access article distributed under the terms and conditions of the Creative Commons Attribution (CC BY) license (https:/ / creativecommons.org/licenses/by/ $4.0 /)$.

\begin{abstract}
More than half of food waste is generated at the household level, and therefore, it is important to tackle and attempt to solve the problem of consumer food waste. This study aimed to identify factors differentiating high food wasters from low food wasters. A large-scale survey was conducted in Lithuania. A total of 1001 respondents had participated in this survey and were selected using a multi-stage probability sample. Data were collected through face-to-face interviews using a structured questionnaire. Binary logistic regression modelling was used to analyse the effect of socio-demographics, food-related behaviours, attitudes towards food waste, and knowledge of date labelling on levels of food waste. Impulse buying, inappropriate food preparation practices, non-consumption of leftovers, lack of concern about food waste, and worry about food poisoning were related to higher food waste. On the other hand, correct planning practices and knowledge of date labelling were related to lower food waste. The findings of this study have practical implications for designing interventions aimed at reducing consumer food waste.
\end{abstract}

Keywords: food waste; households; food-related behaviours; attitudes towards food waste; knowledge of expiry dates; socio-demographics

\section{Introduction}

In the world today, food waste is recognised as an issue that must be overcome. Food waste causes negative environmental, economic, and social consequences. When food is thrown away, a huge amount of resources, such as land, water, and energy, that have been used in the production of that food are lost [1,2]. Furthermore, food that ends up in landfills produces landfill gas, mainly methane and $\mathrm{CO}_{2}$, contributing to climate change [3] Apart from damage to the environment, food waste represents a considerable monetary loss for all individuals and organisations involved in the food supply chain [4]. Finally, food waste is an ethical problem, as it presents a missed opportunity to feed millions of undernourished people [5-7].

Developing and developed countries dissipate almost the same amount of food, and the difference is that, in developing countries, the largest food losses occur at post-harvest and processing levels, while in developed countries, most of the food is wasted at retailer and consumer levels [8]. It is estimated that, in the EU, approximately 88 million tonnes of food are wasted yearly, and more than half of this waste $(53 \%)$ occurs at the household level [9].

Consumer food waste is of particular concern as it is mostly avoidable food waste, which means food that could have been consumed but, unfortunately, has been thrown away. Since households are responsible for the largest share of food waste, it is of major importance to investigate consumer food waste behaviour and its determinants. The existing literature indicates the importance of certain factors that affect consumer food waste. These 
factors encompass behavioural factors (behaviours related to food provisioning), psychological factors (i.e., attitudes or beliefs), knowledge, as well as socio-demographics [10,11].

\subsection{Food-Related Behaviours Preventing or Promoting Food Waste}

Food waste at the household level is not the outcome of a single behaviour, but rather it results from multiple behaviours. Food-related behaviours that influence food waste in households are usually grouped into the following stages: planning, shopping, storage, preparation, and consumption of food $[7,12,13]$.

When it comes to the planning stage, the behaviours that tend to be considered include making a shopping list, estimating quantities of food items prior to shopping, checking food inventories before shopping, planning meals in advance $[7,10,12]$. Correct planning can prevent people from buying more food than they need, thereby decreasing the likelihood of spoilage [7]. However, the results of studies relating planning behaviours to wasted food are mixed. While some studies have found a correlation between more frequent participation in planning behaviours and lower levels of food waste [14-17], but others have not [18-21].

As regards the shopping stage, people often follow a routine of buying more food than they actually need to [22-24], which, in turn, affects the amount of food waste. Buying too much food leads to food getting thrown away due to spoilage, becoming expired, developing a bad smell or taste, and having been forgotten in the fridge and cupboards [25]. Over-buying is considered a key barrier to the reduction in food waste and is associated with impulse buying [11]. There are studies that have confirmed that higher levels of overbuying lead to higher levels of food waste [14,17,26-29]. However, Elimelech et al. [20] have reported that unplanned shopping is not necessarily associated with food waste behaviour, and Giordano et al. [30] have found no evidence of either a positive or negative relationship between the purchase of discounted food products and the amount of food wasted in households.

With respect to the storage stage, some improper habits contribute to food waste. People often store food under sub-optimal conditions, which leads to full potential shelflife not being achieved [31,32]. Improper food storage conditions inevitably cause food to spoil more quickly $[25,33]$. Storage times and low visibility of food products in the fridge and cupboards also result in food waste. Too long storage [34,35] and disorganised storage space $[16,36,37]$ increase the risk of food being forgotten and thrown away after a certain time.

When analysing the preparation stage, one of the most important behaviours that contribute to food waste is over-preparation [28,38-40]. This behaviour can be accidental or unintentional, but it may be intentional as well. There are cases where people find it difficult to know how much to cook per person or to cook the right portions [33,41]. In some cases, people wish to demonstrate their hospitality to guests, make sure that members of their household have a meal that satisfies their wishes [35,38], or simply prefer to serve too much than not enough [41].

Regarding the consumption stage, eating leftovers is considered a practice that prevents food waste. Some studies have confirmed that those who eat leftovers more often generate less food waste $[13,27]$. The main reasons for leftovers not being eaten are the prejudice against them or freshness preference (people want to eat something new and fresh) and safety issues (people are unsure whether leftovers are safe to eat) $[33,35,37]$.

\subsection{Attitudes towards Food Waste}

Attitude refers to how an individual assesses the throwing away of food, and it includes feelings or emotions and thoughts or beliefs that this behaviour evokes [7].

Overall, people do not like wasting food, and they view this behaviour as morally wrong, which leads to a feeling of guilt $[23,38,42-45]$. There are studies that have found that people who feel guilt generate less food $[26,46]$. 
People experience negative feelings as they see food waste as a monetary loss $[12,38,42,43]$. In addition, people acknowledge that food waste causes negative environmental and social consequences $[26,38,44]$. Several studies have confirmed that the more negative attitudes people hold towards food waste, the less they waste food $[13,14,27]$.

At the same moment, there are people who lack concern about food waste as an issue. They believe that food waste is inevitable, has no negative effects on the environment as it is natural and biodegradable, or that there are bigger problems to worry about $[38,42,47]$.

Some people do not try to reduce the amount of food they throw away or are not bothered about food waste because they worry about food poisoning [38,42,48]. People think that throwing away food that has passed its label date reduces the odds of foodborne illness [44]. Indeed, concerns over possible health risks are among the goal conflicts that hinder a reduction in food waste [49].

\subsection{Knowledge of Expire Dates}

Consumers do not fully understand 'use-by' and 'best-before' dates [50-52] or are aware of the meaning of these dates [42]. There are studies that have investigated the relationship between knowledge of date labelling and food waste, and their results are mixed. Some studies have found that knowledge of expiry dates has significant effects on behaviours related to lower food waste [40,46,53]. However, Visschers et al. [18] have not reported a direct relationship between knowledge of expiry dates and the amount of food wasted in households.

\subsection{Socio-Demographics and Food Waste}

There is no consistency over whether gender has a significant effect on the amount of food waste produced at the household level. While some studies have reported that women waste more $[18,25,39,40]$, others have indicated that women waste less $[54,55]$. However, there are also studies that have reported no significant relationship between gender and the amount of food wasted in households [13,28,29,56-58].

Most studies have reported the negative correlation between age and the amount of food waste produced at the household level: the older the people, the less they report wasting [13,18,29,46,55-57,59-61]. Other studies have found opposite results, indicating that the production of food waste increases with age [54] or persons aged 65 years or over waste the most [62]. There are also studies that have reported no significant relationship between age and the amount of food wasted in households [28,40,58]. However, the majority of studies have come to the conclusion that elderly people tend to throw away less food. This can primarily be explained by the fact that households of elderly people comprise a smaller number of persons. Moreover, elderly people have different attitudes towards food as they or their parents have experienced periods of food shortages. Additionally, these people have more time and better food management knowledge and skills and are often financially constrained [63-65].

With respect to education, some studies have reported that households with more educated individuals produce more food waste [55,59]. Secondi et al. [55] attribute this phenomenon either to the higher income of better-educated people, which means that these people can simply afford to waste food or to the inability of less-educated people to accurately estimate the amount of food they waste in their households. Marangon et al. [59] suggest that people with higher education devote a great deal of time to work, so they usually shop once a week in hypermarkets or supermarkets, which increases the likelihood of food waste in their households. Other studies, however, have indicated that individuals with a university degree waste the least [62] or that education does not have a significant effect on the amount of food waste produced at the household level $[13,18,25,28,29,40,43,54,57,61,66]$.

Regarding employment status, previous studies have come to divergent conclusions. Some studies have found that employment status has a significant effect on the amount of food wasted in households: employed people tend to waste more food [54,56], and unem- 
ployed people tend to waste less food [55,61]. Employed people usually have adequate financial resources and are not concerned about losing money by wasting food; in addition, they also have less time and focus devoted to worrying about food waste [44,56]. However, there are also studies that have reported no significant association between employment status and food waste behaviour [58].

As for income, the evidence is also mixed. Some studies have found that lower amounts of food waste are associated with lower income [17,40,46,56,57,62]. However, Setti et al. [67] have revealed that mid-to-low-income consumers purchase higher amounts of lower quality food and waste more. Other studies have stated that there is no correlation between income and the amount of food waste at the household level [13,29,58].

Numerous studies have shown that household size has a significant effect on the amount of food wasted in households. Larger households produce more food waste in total than smaller ones, while on a per capita basis, the amount of food waste decreases with an increasing number of persons in a household $[21,25,26,34,39,66]$.

Many studies have confirmed that households with children waste more food $[17,18,26,43,46,57-59,66]$. This phenomenon could be explained by the fact that these families face time and money constraints [26], as well as meet challenges related to unpredictable eating patterns and preferences of children [34,63]. Moreover, parents tend to buy, cook or prepare more food than is required and pay great attention to food quality and safety [63].

In relation to location, some studies have stated that households in urban areas waste more food $[55,66,68]$. However, there are also studies that have found no evidence that levels of food waste differ between people living in urban and rural areas $[57,60]$.

\subsection{Aim of the Study}

In the light of the above, one could be concluded that consumer food waste has received increasing scientific attention. Previous studies have greatly contributed to the understanding of consumer food waste behaviour and revealed a variety of factors that affect consumer food waste. However, some of the studies are qualitative, whereas some of the quantitative studies measure a limited number of factors and their relation to food waste [69]. In recent years has there been an increase in the number of studies including more factors and relating their effects on food waste in more detail. However, the findings of the studies are mixed and sometimes contradictory. It is clear that further work needs to be conducted in this area to gain a better understanding of factors to be considered when aiming to reduce food waste at the household level.

The aim of the present study is to identify the key factors that are related to higher or lower consumer food waste, thus differentiating high food wasters from low food wasters. Drawing from a large-scale consumer survey, in this study, the effect of foodrelated behaviours, attitudes towards food waste, knowledge of date labelling, and sociodemographics on levels of food waste is analysed.

From a theoretical point of view, the present study extends existing research explaining consumer food waste behaviour by combining food-related behaviours, psychological factors, and knowledge. Next to the scientific contribution, the findings of this study are important for policy-makers and interested stakeholders when designing interventions to reduce food waste at the household level using policy, changes in business practises, and education.

The present study summarises the results of the first known nationally representative consumer survey focused on food waste behaviour in Lithuania. Therefore, this study is a starting point for further analysis of food waste at the household level and contributes to the knowledge on the topic and policy-making. A better understanding of factors that are important for explaining Lithuanian consumer food waste behaviour is necessary to ensure that interventions designed to reduce food waste are effective and efficient. The findings of the present study provide a basis upon which future research can be compared. 


\section{Materials and Methods}

\subsection{Data Collection and Sample}

Data used in this study were obtained from a large-scale survey of Lithuanian residents aged 18 years or over. A multi-stage probability sampling strategy was used to identify a representative sample of 1001 persons. Participants were selected and interviewed by professionals of a public opinion and market research company, which ensured that the sample was representative of the Lithuanian general population in terms of geographical location, gender, and age. Face-to-face interviews (using a structured questionnaire) were conducted in participants' own homes at the end of 2017. When interviewers arrived at participants' homes, they first explained the purpose and background of the study. Then, all participants completed the screening questions, and those who were not responsible for at least part of the shopping and cooking of food in their household were not asked to participate in the survey. Prior to answering the survey questions, eligible participants were informed that their personal data (names, surnames, etc.) would be omitted in the questionnaire. Interviewers did not mark personal data in the questionnaire to ensure confidentiality and anonymity. The research team received only anonymous data of the sample.

Out of 1001 respondents, $58 \%$ were women, and $42 \%$ were men. The residents of urban areas represented slightly more than two-thirds of the sample $(69 \%)$, while the residents of rural areas represented slightly less than one-third (31\%). The distribution of participants by age was as follows: $27 \%$ were aged $18-29$ years, $32 \%$ were aged $30-45$ years, $23 \%$ were aged $46-65$ years, and $18 \%$ were aged 66 years or over. The majority of respondents had secondary or higher education $(87 \%)$, while the other $(13 \%)$ had basic or primary education. Most participants were employed (65\%), a small proportion (4\%) was unemployed, and the remaining $(31 \%)$ were categorised as other (students, homemakers, people who are retired or who have disabilities, or other people not in the labour force). Concerning the net monthly household income of respondents, 12\% reported an income below EUR 315, $56 \%$ indicated an income of EUR 315-726, and 32\% reported an income above EUR 726. The household composition was as follows: $18 \%$ one-person households, $39 \%$ households with no children under the age of 18 years living in, and $43 \%$ households with children.

\subsection{Measurements}

The questionnaire used in this study was created based on a thorough review of the existing literature. It contained measures of self-reported food waste behaviour, foodrelated behaviours, attitudes towards food waste, and knowledge of date labelling, as well as socio-demographics. These measures were part of a larger data set, and only the measures relevant to the present study were described here. All items regarding food-related behaviours and attitudes towards food waste were rated on a 7-point Likert frequency or agreement scale.

The initial questionnaire was discussed among the research team and was modified after a few rounds of discussion. Prior to carrying out the survey, the questionnaire was tested for participant comprehension using face-to-face interviews with a small number of people $(\mathrm{N}=8)$. The participants included a mix of ages and household composition. Following each interview, the questions were discussed, and minor wording amendments were made. Data collected from testing were not included in the final analysis.

\subsection{Self-Reported Food Waste Behaviour}

In this study, self-reporting of food waste was used. Self-reporting has its limitations as it cannot assess how people actually behave. Individuals providing self-report information may not respond truthfully either because they wish to present themselves in a socially acceptable manner or because they cannot remember accurately [70]. However, the present study was not intended to estimate the exact amounts of food waste at the household level. As in previous studies, in this study, self-reporting was used to determine whether consumers fall at the high or low end of food waste levels [28,69]. 
Self-reported food waste behaviour was measured by asking respondents to estimate the amount of food they waste in their household per week based on six predefined categories: nothing; less than $250 \mathrm{~g}$; 250-500; 500-1000; 1000-2000; and more than $2000 \mathrm{~g}$ (these categories were taken from previous studies [34,71]. Before answering this question, participants were instructed to imagine that a typical portion of one medium-sized cucumber, or apple, or banana, or orange weighs 100-125 g. In addition, respondents were asked to keep in mind only avoidable food waste (food that could have been eaten but has been thrown away) [72].

Respondents were ranked as either low food wasters or high food wasters, depending upon their response to food waste behaviour. Consistent with previous studies [56,69], low food wasters were those who reported low food waste (in this study, less than $250 \mathrm{~g}$ per week) and high food wasters were those who reported high food waste (in this study, $250 \mathrm{~g}$ or more per week).

\subsection{Food-Related Behaviours}

Planning behaviours were measured using four items selected from previous studies $[14,43,47,73]$ : 'I make a shopping list before shopping', 'I check the fridge and cupboards before shopping', 'I estimate quantities needed before shopping', and 'I plan meals in advance'. All items were merged into one 'Correct planning practices' score (Cronbach's alpha 0.829).

Food shopping behaviours were measured using two items developed based on previous studies [14,42,47]: 'I buy too much food (more than I need or can eat) when shopping', and 'I buy food items that I did not intend to buy'. Both items were merged into one 'Impulse buying' score (Cronbach's alpha 0.800).

Food storing behaviours were measured using two items constructed from previous studies [37,42]: 'I organize the fridge and cupboards where food is stored', and 'I check the expiry date of food stored in the fridge and cupboards'. The items were merged into one 'Adequate food storing practices' score (Cronbach's alpha 0.894).

Food preparation behaviours were measured using two items, adapted from previous studies [42,43]: 'I make too much food that is not eaten', and 'I do not cook food before it goes bad or expires'. The two items were merged into one 'Inappropriate food preparation practices' score (Cronbach's alpha 0.741).

Leftover consumption behaviours were measured using two items, adjusted from previous studies $[27,42,43]$ 'I find it difficult to transform leftovers into new meals', and 'No one in our household likes eating leftovers, so they go to waste'. The two items were merged into one 'Non-consumption of leftovers' score (Cronbach's alpha 0.896).

\subsection{Attitudes towards Food Waste}

Lack of concern about food waste was measured using five items, derived from previous studies $[14,42,43,47]$ : 'I do not really worry about the amount of food that I throw away', 'I do not really worry about the cost of the food I throw away', 'I believe that food waste is inevitable', 'I think that there are far more important problems than food waste', and 'I think that, given the scale of food waste, my individual actions would not make much difference'. The five items were merged into one 'Lack of concern about food waste' score (Cronbach's alpha 0.881).

The feeling of guilt was measured using the item 'I feel guilty throwing away food'. This item was based on Stefan et al. [14].

Worry about food poisoning was measured using the item 'I think I would rather throw away food than risk eating unsafe food and getting sick'. This item was based on Cox and Downing [42] and Principato et al. [48].

\subsection{Knowledge of Date Labelling}

Knowledge of 'use-by' and 'best-before' dates was measured using five items each, taken from Flash Eurobarometer 425 (2015). Respondents were asked to indicate what they 
thought the date labelling meant by selecting only one option for each type of date (for each type of date, only one item was correct, while the others were incorrect or 'Don't know'). The responses were transformed into a binary variable of 0 (incorrect or 'Don't know') and 1 (correct). A common binary index of knowledge of expiry dates was computed and coded as 0 if responses on the meaning either of one type of date or of both were incorrect or as 1 if responses on the meaning of both dates were correct.

\subsection{Socio-Demographics}

Socio-demographics included gender (female; male), location (urban areas; rural areas), age group (18-29; 30-45; 46-65; and 66 or over), education (primary or basic; secondary or higher), employment status (employed; unemployed; and other), net monthly household income (below EUR 315; EUR 315-726; and above EUR 726), and household composition (one-person households; households with no children under the age of 18 years; and households with children).

\subsection{Statistical Analyses}

Data were analysed using bivariate and multivariate analyses. First, descriptive statistics were performed to examine the distribution of self-reported food waste behaviour. Second, Pearson Chi-square tests with post hoc testing (adjusted $p$-values (Bonferroni method)) were conducted to assess statistically significant differences between the food waste groups on socio-demographics. Finally, a multivariate binary logistic regression model was fitted using the enter procedure to determine which factors uniquely predict food waste. Two models were estimated: model 1 consisted of only socio-demographics; model 2 consisted of socio-demographics, food-related behaviours, attitudes towards food waste, and knowledge of date labelling. Model fitness was assessed using the omnibus Chi-square test, the proportion of respondents correctly classified as high food wasters versus low food wasters, as well as sensitivity and specificity ratios. Adjusted odds ratios (ORs) were presented, together with their 95\% confidence intervals (CIs). Both models were tested for multicollinearity, outliers, and leverage points. No problems were found with regard to these aspects. All statistical analyses were conducted using SPSS (version 22 for Windows). Variables were considered significant if the $p$-value was less than 0.05.

\section{Results}

\subsection{Levels of Self-Reported Food Waste}

In terms of the reported amount of food waste per week, an estimated $16.7 \%$ of all respondents indicated that they did not waste food at all. Close to one-third (30.4\%) of the sample claimed that they waste less than $250 \mathrm{~g}$. About the same proportion (30.6\%) of all respondents pointed out that they waste $250-500 \mathrm{~g} .16 .8 \%$ of the sample said they waste 500-1000 g, and 5.2\% said they waste 1000-2000 g. Only $0.4 \%$ of all respondents revealed that they waste more than $2000 \mathrm{~g}$. Thus, slightly less than half of the participants (47.1\%) were low food wasters, as they reported wasting less than $250 \mathrm{~g}$ of food per week, and slightly more than half of the participants (52.9\%) were high food wasters, as they reported wasting more than $250 \mathrm{~g}$ of food per week.

\subsection{Descriptive Differences between High Food Wasters and Low Food Wasters on Socio-Demographics}

The results of bivariate analyses are presented in Table 1 . With respect to age, a significantly larger proportion of high food wasters were respondents aged 30-45 years, whereas a significantly larger proportion of low food wasters were respondents aged 66 years or over. Concerning employment status, high food wasters were significantly more likely to be employed, while low food wasters were significantly more likely to be not in the labour force. In terms of income, a significantly larger proportion of high food wasters consisted of respondents from households with high income, whereas a significantly larger proportion of low food wasters consisted of respondents from households with low income. 
As regards household composition, respondents from households with children were significantly more likely to report higher food waste, while respondents from one-person households were significantly more likely to report lower food waste. No significant differences were observed for gender, location, and education.

Table 1. Socio-demographic comparisons between low food wasters and high food wasters $(\mathrm{N}=1001)$.

\begin{tabular}{|c|c|c|c|c|c|}
\hline \multirow{2}{*}{\multicolumn{2}{|c|}{ Socio-Demographic Characteristic }} & \multicolumn{2}{|c|}{ Low Food Wasters } & \multicolumn{2}{|c|}{ High Food Wasters } \\
\hline & & $n=471$ & $\%$ & $n=530$ & $\%$ \\
\hline \multirow{2}{*}{ Gender } & Female & 267 & 56.7 & 318 & 60.0 \\
\hline & Male & 204 & 43.3 & 212 & 40.0 \\
\hline \multicolumn{6}{|c|}{$\chi^{2}=1.126, p=0.289$} \\
\hline \multirow{2}{*}{ Location } & Urban areas & 313 & 33.5 & 371 & 30.0 \\
\hline & Rural areas & 158 & 66.5 & 159 & 70.0 \\
\hline \multicolumn{6}{|c|}{$\chi^{2}=1.449, p=0.229$} \\
\hline \multirow{4}{*}{ Age group } & $18-29$ & 113 & 24.0 & 156 & 29.4 \\
\hline & $30-45$ & 129 & 27.4 & 195 & $36.8 *$ \\
\hline & $46-65$ & 105 & 22.3 & 126 & 23.8 \\
\hline & 66 or over & 124 & $26.3 *$ & 53 & 10.0 \\
\hline \multicolumn{6}{|c|}{$\chi^{2}=47.394, p<0.001$} \\
\hline \multirow{2}{*}{ Education } & Primary or basic & 65 & 13.8 & 62 & 11.7 \\
\hline & Secondary or higher & 406 & 86.2 & 468 & 88.3 \\
\hline \multicolumn{6}{|c|}{$\chi^{2}=0.995, p=0.319$} \\
\hline \multirow{3}{*}{ Employment status } & Employed & 269 & 57.1 & 386 & $72.8^{*}$ \\
\hline & Unemployed & 22 & 4.7 & 18 & 3.4 \\
\hline & Other & 180 & $38.2 *$ & 126 & 23.8 \\
\hline \multicolumn{6}{|c|}{$\chi^{2}=27.446, p<0.001$} \\
\hline \multirow{3}{*}{$\begin{array}{l}\text { Net monthly } \\
\text { household income }\end{array}$} & Low & 80 & $17.0 *$ & 40 & 7.5 \\
\hline & Average & 270 & 57.3 & 288 & 54.3 \\
\hline & High & 121 & 25.7 & 202 & $38.1 *$ \\
\hline \multicolumn{6}{|c|}{$\chi^{2}=30.856, p<0.001$} \\
\hline \multirow{3}{*}{ Household composition } & One-person & 109 & $23.1 *$ & 66 & 12.5 \\
\hline & Without children & 184 & 39.1 & 210 & 39.6 \\
\hline & With children & 178 & 37.8 & 254 & $47.9 *$ \\
\hline
\end{tabular}

${ }^{*}$ The proportion of respondents in that category from that group (either low food wasters or high food wasters) is significantly larger than the proportion of respondents from the other group.

\subsection{Factors Statistically Differentiating High Food Wasters from Low Food Wasters}

Since there were no controls for the extraneous factors at the bivariate level, multivariate analyses were performed in order to determine which factors uniquely differentiate high food wasters and low food wasters. Logistic regression was utilised to model the relationships of measured and calculated variables with high or low food waste as the response variable. In model 1, only socio-demographics were entered. In model 2, foodrelated behaviours, attitudes towards food waste, and knowledge of date labelling were added. The dependent variable was coded as 0 'low food waster' and 1 'high food waster'. All explanatory variables proposed to be related to food waste are depicted in Table 2. 
Table 2. Descriptive statistics of explanatory variables $(\mathrm{N}=1001)$.

\begin{tabular}{|c|c|}
\hline Variable & Mean \\
\hline Gender $(1=$ female, $0=$ male $)$ & 0.58 \\
\hline Location $(1=$ urban areas, $0=$ rural areas $)$ & 0.68 \\
\hline \multicolumn{2}{|l|}{ Age group } \\
\hline $18-29(1=18-29,0=$ otherwise $)$ & 0.27 \\
\hline $30-45(1=30-45,0=$ otherwise $)$ & 0.32 \\
\hline $46-65(1=46-65,0=$ otherwise $)$ & 0.23 \\
\hline 66 or over ( $1=66$ or over, $0=$ otherwise $)$ & 0.18 \\
\hline Education ( 1 = secondary or higher, 0 = primary or basic $)$ & 0.87 \\
\hline Employment status & \\
\hline Employed ( $1=$ employed, $0=$ otherwise $)$ & 0.65 \\
\hline Unemployed ( $1=$ unemployed, $0=$ otherwise $)$ & 0.04 \\
\hline Other $(1=$ other, $0=$ otherwise $)$ & 0.31 \\
\hline \multicolumn{2}{|l|}{ Net monthly household income } \\
\hline Low $(1=$ low income, $0=$ otherwise $)$ & 0.12 \\
\hline Average ( $1=$ average income, $0=$ otherwise $)$ & 0.56 \\
\hline High $(1=$ high income, $0=$ otherwise $)$ & 0.32 \\
\hline Household composition & \\
\hline One-person $(1=$ one-person, $0=$ otherwise $)$ & 0.18 \\
\hline Without children $(1=$ without children, $0=$ otherwise $)$ & 0.39 \\
\hline With children $(1=$ with children, $0=$ otherwise $)$ & 0.43 \\
\hline $\begin{array}{l}\text { Correct planning practices } \\
\text { (7-point frequency scale) }\end{array}$ & 4.27 \\
\hline $\begin{array}{c}\text { Impulse buying } \\
\text { (7-point frequency scale) }\end{array}$ & 3.69 \\
\hline $\begin{array}{l}\text { Adequate food storing practices } \\
\text { (7-point frequency scale) }\end{array}$ & 5.30 \\
\hline $\begin{array}{l}\text { Inappropriate food preparation practices } \\
\text { (7-point frequency scale) }\end{array}$ & 3.20 \\
\hline $\begin{array}{l}\text { Non-consumption of leftovers } \\
\text { (7-point agreement scale) }\end{array}$ & 2.73 \\
\hline $\begin{array}{c}\text { Feeling of guilt } \\
\text { (7-point agreement scale) }\end{array}$ & 4.40 \\
\hline $\begin{array}{l}\text { Lack of concern about food waste } \\
\text { (7-point agreement scale) }\end{array}$ & 3.66 \\
\hline $\begin{array}{l}\text { Worry about food poisoning } \\
\text { (7-point agreement scale) }\end{array}$ & 5.03 \\
\hline $\begin{array}{l}\text { Knowledge of expiry dates }(1=\text { awareness of the meaning of both } \\
\text { 'use-by' and 'best-before' dates, } 0=\text { non-awareness of the meaning of } \\
\text { either one type of date or of both, or 'Don't know') }\end{array}$ & 0.24 \\
\hline
\end{tabular}

Table 3 presents the results of two binary logistic regression models. Model 1 shows that when all socio-demographics were included in the analysis, only age, income, and household composition had a significant relationship with the food waste groups. With respect to age, respondents from the young and middle-aged groups (18-29, 30-45, or 46-65), as compared to respondents aged 66 years or over, were more likely to belong to the high food waste group. In terms of income, respondents from households with high income were more likely to belong to the high food waste group than respondents from households with low income. Concerning household composition, respondents from households without and with children, as compared to respondents from one-person households, were more likely to belong to the high food waste group. Other socio-demographic 
characteristics, such as gender, location, education, and employment status, failed to reach significance.

Table 3. Logistic regression of factors differentiating high food wasters from low food wasters.

\begin{tabular}{|c|c|c|c|c|c|c|}
\hline \multirow{2}{*}{$\begin{array}{c}\text { Variable } \\
\text { Constant }\end{array}$} & \multicolumn{3}{|c|}{ Model 1} & \multicolumn{3}{|c|}{ Model 2} \\
\hline & B & Sig & $\operatorname{Exp}(B)(95 \%$ CI $)$ & B & Sig & $\operatorname{Exp}(B)(95 \%$ CI) \\
\hline $\begin{array}{c}\text { Gender } \\
\text { Female } \\
\text { Male (reference) }\end{array}$ & 0.183 & 0.178 & $1.201(0.920-1.568)$ & 0.289 & 0.056 & $1.335(0.992-1.795)$ \\
\hline $\begin{array}{c}\text { Location } \\
\text { Urban areas } \\
\text { Rural areas (reference) }\end{array}$ & 0.061 & 0.403 & $1.063(0.921-1.226)$ & 0.073 & 0.369 & $1.075(0.918-1.260)$ \\
\hline $\begin{array}{c}\text { Age group } \\
18-29 \\
30-45 \\
46-65 \\
66 \text { or over (reference) }\end{array}$ & $\begin{array}{l}0.974 \\
0.874 \\
0.679\end{array}$ & $\begin{array}{l}0.000 \\
0.001 \\
0.007\end{array}$ & $\begin{array}{l}2.648(1.684-4.166) \\
2.398(1.445-3.979) \\
1.972(1.200-3.242)\end{array}$ & $\begin{array}{l}0.587 \\
0.618 \\
0.417\end{array}$ & $\begin{array}{l}0.022 \\
0.031 \\
0.138\end{array}$ & $\begin{array}{l}1.798(1.090-2.967) \\
1.856(1.057-3.259) \\
1.517(0.875-2.632)\end{array}$ \\
\hline $\begin{array}{c}\text { Education } \\
\text { Primary or basic (reference) } \\
\text { Secondary or higher }\end{array}$ & -0.247 & 0.244 & $0.781(0.515-1.184)$ & -0.130 & 0.576 & $0.878(0.557-1.385)$ \\
\hline $\begin{array}{l}\text { Employment status } \\
\text { Employed (reference) } \\
\text { Unemployed } \\
\text { Other }\end{array}$ & $\begin{array}{l}-0.254 \\
-0.324\end{array}$ & $\begin{array}{l}0.184 \\
0.349\end{array}$ & $\begin{array}{l}0.776(0.533-1.128) \\
0.723(0.367-1.425)\end{array}$ & $\begin{array}{l}-0.209 \\
-0.162\end{array}$ & $\begin{array}{l}0.323 \\
0.677\end{array}$ & $\begin{array}{l}0.811(0.536-1.228) \\
0.878(0.397-1.822)\end{array}$ \\
\hline $\begin{array}{c}\text { Net monthly household income } \\
\text { Low (reference) } \\
\text { Average } \\
\text { High }\end{array}$ & $\begin{array}{l}0.458 \\
0.682 \\
\end{array}$ & $\begin{array}{l}0.054 \\
0.011 \\
\end{array}$ & $\begin{array}{l}1.581(0.991-2.522) \\
1.977(1.166-3.352)\end{array}$ & $\begin{array}{l}0.609 \\
0.678 \\
\end{array}$ & $\begin{array}{l}0.022 \\
0.023 \\
\end{array}$ & $\begin{array}{l}1.839(1.092-3.097) \\
1.969(1.097-3.535)\end{array}$ \\
\hline $\begin{array}{l}\text { Household composition) } \\
\text { One-person (reference) } \\
\text { Without children } \\
\text { With children }\end{array}$ & $\begin{array}{l}0.487 \\
0.429\end{array}$ & $\begin{array}{l}0.016 \\
0.037 \\
\end{array}$ & $\begin{array}{l}1.628(1.095-2.419) \\
1.536(1.027-2.298)\end{array}$ & $\begin{array}{l}0.388 \\
0.344\end{array}$ & $\begin{array}{l}0.080 \\
0.130\end{array}$ & $\begin{array}{l}1.473(0.955-2.274) \\
1.411(0.904-2.201)\end{array}$ \\
\hline Correct planning practices & & & & -0.230 & 0.000 & $0.794(0.704-0.897)$ \\
\hline Impulse buying & & & & 0.127 & 0.027 & $1.136(1.015-1.271)$ \\
\hline Adequate food storing practices & & & & -0.032 & 0.564 & $0.968(0.867-1.081)$ \\
\hline Inappropriate food preparation practices & & & & 0.187 & 0.001 & $1.206(1.077-1.350)$ \\
\hline Non-consumption of leftovers & & & & 0.261 & 0.000 & $1.298(1.166-1.446)$ \\
\hline Feeling of guilt & & & & -0.012 & 0.794 & $0.988(0.903-1.081)$ \\
\hline Lack of concern about food waste & & & & 0.163 & 0.007 & $1.177(1.046-1.323)$ \\
\hline Worry about food poisoning & & & & 0.130 & 0.007 & $1.139(1.035-1.252)$ \\
\hline Knowledge of expire dates & & & & -0.368 & 0.040 & $0.692(0.487-0.984)$ \\
\hline Nagelkerke pseudo $\mathrm{R}^{2}$ & & & 0.095 & & & 0.276 \\
\hline Model Chi-square (sig) & & & $73.803(0.000)$ & & & $232.238(0.000)$ \\
\hline Sensitivity & & & 72.8 & & & 72.3 \\
\hline Specificity & & & 48.8 & & & 66.7 \\
\hline Overall percentage correctly classified & & & 61.5 & & & 69.6 \\
\hline
\end{tabular}

Model 2, the extended one, shows that added variables (food-related behaviours, attitudes towards food waste, and knowledge of date labelling) contributed to the explanation of the reported amount of food waste. After introducing these variables, age and income 
remained significantly related to the food waste groups, whereas household composition was no longer significantly related to the food waste groups. Respondents aged 18-29 or 30-45 years were 1.8 and 1.9 times, respectively, more likely to belong to the high food waste group than respondents aged 66 years or over. Respondents from households with average and high income were 1.8 and 2.0 times, respectively, more likely to belong to the high food waste group than respondents from households with low income. Food-related behaviours, such as correct planning practices, impulse buying, inappropriate food preparation practices, and non-consumption of leftovers, had a significant relationship with the food waste groups. A one-unit increase in scores reflecting impulse buying, inappropriate food preparation practices, and non-consumption of leftovers significantly increased the odds of belonging to the high food waste group by $13.6 \%, 20.6 \%$, and $29.8 \%$, respectively. On the other hand, a one-unit increase in the correct planning practices score was related to a $20.6 \%$ decrease in the odds of belonging to the high food waste group. Lack of concern about food waste and worry about food poisoning also had a significant relationship with the food waste groups. A one-unit increase in scores reflecting lack of concern about food waste and worry about food poisoning significantly increased the odds of belonging to the high food waste group by $17.7 \%$ and $13.9 \%$, respectively. Lastly, knowledge of date labelling was related to a $30.8 \%$ decrease in the odds of belonging to the high food waste group.

Overall, the final model correctly categorised $69.6 \%$ of high and low food wasters and was significant, $\chi^{2}(21, \mathrm{~N}=1001)=232.238, p<0.001$. Furthermore, this model predicted both categories with approximately the same success, correctly predicting $72.3 \%$ of high food wasters and $66.7 \%$ of low food wasters.

\section{Discussion}

The findings of the present study in relation to the self-reported amount of food wasted in the households are similar to previous studies. Many studies have indicated that most people report throwing away only small amounts of food $[17,21,28,34,43,50,61,65,74]$. In this study, one in six respondents reported not wasting food at all. This confirms that, when people are asked to estimate the amount of food waste in their household, they are linked to providing underestimated values. Therefore, questionnaires are not reliable methods for estimating the quantities of food waste at the household level [20,74-77]. In order to quantify food waste in households, other methods, such as diaries, waste composition analysis, are highly recommended. Nevertheless, there are studies that have found that the amount of food waste reported on the questionnaires is correlated with the amount of food waste measured using food waste diaries or actual collection of food waste [70,78]. Questionnaires are useful tools for exploring the determinants of consumer food waste behaviour [13,28,78].

In relation to socio-demographics, the findings of this study indicated that they could affect the reported amount of food waste to some extent. Although the results of the bivariate analyses revealed that low food wasters and high food wasters significantly differed from each other in several socio-demographics, the results of multivariate analyses showed that when all socio-demographics and other variables of known importance for the analysis of food waste (food-related behaviours, attitudes towards food waste, and knowledge of expiry dates) were included, only age and income had a significant relationship with the food waste groups.

Older people have a natural attitude towards saving, possess better food management knowledge and skills, and often exist on limited financial resources. Many previous studies have confirmed that young people waste food more than older people $[13,18,29,46,61]$. A similar trend was found in this study, as younger respondents, relative to older ones, had a significantly increased likelihood of reporting higher food waste.

Consistent with some previous studies [17,40,46,62], this study showed a significant association between household income and the reported amount of food waste. Respondents from households with higher income were more likely to report higher food waste. 
These people can simply afford to waste food as to them buying food does not represent a significant financial cost.

Socio-demographics play only a limited role in explaining food waste at the household level $[29,61,66]$. The attitudes and food-related behaviours appear to be more important $[12,64]$.

The present study found that the lower the level of correct planning practices, and the higher the level of impulse buying, inappropriate food preparation practices, or nonconsumption of leftovers, the higher the probability of reporting higher food waste was. These findings are in line with previous studies: Stefan et al. [14] and Romani et al. [16] have confirmed that planning routines have a negative effect on food waste; Diaz-Ruiz et al. [15] have reported a significant and negative association between purchasing discipline including planning and food waste; Stefan et al. [14], Stancu et al. [27], Falasconi et al. [28], and Janssens et al. [29] have concluded that shopping routines (buying too much) are the main drivers of food waste; Van Geffen et al. [13] have confirmed that higher levels of cooking precisely lead to lower levels of food waste, and Fanelli [40] has shown that cooking too much affects the increase in food waste; Stancu et al. [27] and Van Geffen et al. [13] have revealed that the use of leftovers has a negative impact on food waste. Therefore, food-related behaviours are an important policy target [13].

Some previous studies have confirmed that the more negative the attitudes towards food waste, the less food is wasted $[13,14,27]$. In this study, it was found that respondents who lacked concern about food waste were more likely to report higher food waste. It would appear important to develop interventions designed to strengthen the belief that wasting food is inappropriate $[13,18]$, and everyone should take action to prevent food waste.

Although some previous studies have found that people who feel guilt generate less food [26,46], this study did not find the feeling of guilt to have any significant effect on the reported amount of food waste. Stancu et al. [27] have found no association between moral norms and intended food waste behaviour, suggesting that, although consumers are under great pressure not to waste food, food waste may not provoke strong feelings of regret or remorse.

The present study confirmed the importance of worry about food poisoning as a driver for food waste. Similarly, previous studies have reported that concern about food freshness and fear of foodborne illness increase food waste [42,44,48,49]. Therefore, more knowledge about health risks related to the consumption of leftovers or food products close to or past their expiry dates could decrease the likelihood of consumer food waste [49].

Finally, the present study found that respondents who were aware of the meaning of date labelling were less likely to report higher food waste. This finding is consistent with other studies, concluding that knowledge of expire dates is a factor negatively related to food waste $[40,46,53]$. National authorities and interested stakeholders need to educate consumers in the understanding of 'use-by' and 'best-before' dates and the usability of food products after the 'best-before' date.

\section{Conclusions}

Food waste is considered one of the greatest challenges because of its environmental, economic, and social implications. In developed countries, the largest share of food waste occurs at the household level, and therefore, it is important to tackle and attempt to solve the problem of consumer food waste. The key to reducing food waste at the household level is a better understanding of consumer food waste behaviour.

The present study aimed to compare high food wasters and low food wasters in terms of socio-demographics, behavioural and psychological factors, as well as knowledge of date labelling. The analysis was based on the results of a large-scale survey among a representative sample of the Lithuanian population. A total of 1001 respondents completed a face-to-face questionnaire that collected information on self-reported food waste behaviour, food-related behaviours, attitudes towards food waste, and knowledge of date labelling, as well as socio-demographics. 


\subsection{Main Findings}

This study identified a number of factors that affected levels of food waste. For sociodemographics, only age and household income were significant, with higher food wasters being younger and from households with higher income.

Food-related behaviours were found to be important factors in explaining consumer food waste behaviour. Impulse buying, inappropriate food preparation practices, and non-consumption of leftovers were related to higher food waste, while correct planning routines were related to lower food waste.

In terms of attitudes towards food waste, some psychological factors appeared to serve as obstacles to reducing food waste. Lack of concern about food waste and worry about food poisoning were linked with a higher propensity to waste food.

Finally, knowledge of expiration dates was found to have the potential to reduce food waste. People who were aware of the meaning of date labelling were less likely to waste food.

The results of the present study are highly significant as they contribute to the knowledge regarding consumer food waste behaviour, as well as provide useful information for policy-makers and interested stakeholders in identifying interventions to reduce food waste at the household level. These interventions could include campaigns that provide information and increase awareness about the negative impacts of food waste, prompts against consumer food waste, commitment, information that increase consumer skills for food management, education campaigns that improve consumer knowledge about date labelling. When aiming to prepare effective interventions, it is necessary to identify how consumers could be segmented into different clusters according to their attitudes and behaviours towards food waste as a background for the development of a national strategy for a food waste monitoring system at the household level.

\subsection{Limitations}

As with any study, this study has its limitations that must be clearly acknowledged. First, the present study solely relies on self-reported information, which is vulnerable to response bias in respondents. Participants may have answered in a socially desirable way rather than answering in a way that truly mirrors their attitudes and behaviours related to food waste. Another limitation of this study is the problem of respondents accurately estimating the amount of food they throw away. The measurement relies on participants' memory, which can be faulty. There might have been a social desirability bias leading to the under-reporting of food waste.

\subsection{Future Research Directions}

This study is the first one to provide insights into consumer food waste behaviour in Lithuania and leads to several avenues for future research. As mentioned before, in the present study, consumer food waste behaviour was measured with a self-reported measure. Since self-reports are an imprecise measure of food waste, in future research, it might be beneficial to carry out the quantification of food waste using actual measurements of food waste or food waste diaries and then combine this data with the information gathered through the survey and, thus, identify the factors that are likely to affect food waste.

It is important to point out that this study was conducted before the outbreak of the COVID-19 pandemic that spread across the world in a short time frame. This pandemic resulted in national lockdowns that considerably altered people's lifestyle and food consumption habits. Therefore, it would be of great interest to assess the impact of the COVID-19 pandemic on attitudes and behaviours towards food waste in Lithuanian households.

Author Contributions: Overall conceptualisation, O.E. and G.A.; conceptualisation, O.E., G.A. and A.Š.; writing-original draft preparation, O.E., G.A. and A.̌̌.; writing-review and editing, O.E., G.A., A.Š. and I.P.; writing-specific (sub-) chapters and review, O.E. and G.A.; writing-specific (sub-) chapters, O.E. and G.A.; illustrations, O.E. and G.A.; final editing, O.E., G.A, A.Š. and I.P. All authors have read and agreed to the published version of the manuscript. 
Funding: This research was funded by a grant (No. REP3/2016) 'Food loss suppression, verification, distribution and access to consumers-Empowerment model' from the Research Council of Lithuania.

Institutional Review Board Statement: Ethical review and approval were waived for this study because it did not handle any sensitive personal data. Confidentiality was maintained by responses being completely anonymous and only aggregated data were presented.

Informed Consent Statement: Informed consent was obtained from all subjects involved in the study.

Conflicts of Interest: The authors declare no conflict of interest.

\section{References}

1. Hall, K.D.; Guo, J.; Dore, M.; Chow, C.C. The progressive increase of food waste in America and its environmental impact. PLoS ONE 2009, 4, e7940. [CrossRef]

2. Kummu, M.; De Moel, H.; Porkka, M.; Siebert, S.; Varis, O.; Ward, P.J. Lost food, wasted resources: Global food supply chain losses and their impacts on freshwater, cropland, and fertiliser use. Sci. Total Environ. 2012, 438, 477-489. [CrossRef]

3. Moult, J.A.; Allan, S.R.; Hewitt, C.N.; Berners-Lee, M. Greenhouse gas emissions of food waste disposal options for UK retailers. Food Policy 2018, 77, 50-58. [CrossRef]

4. Thyberg, K.L.; Tonjes, D.J. Drivers of food waste and their implications for sustainable policy development. Resour. Conserv. Recycl. 2016, 106, 110-123. [CrossRef]

5. Bond, M.; Meacham, T.; Bhunnoo, R.; Benton, T. Food Waste within Global Food Systems; Global Food Security: Swindon, UK, 2013.

6. Oliveira, B.; de Moura, A.P.; Cunha, L.M. Reducing food waste in the food service sector as a way to promote public health and environmental sustainability. In Climate Change and Health; Springer: Cham, Switzerland, 2016; pp. 117-132.

7. Van Geffen, L.; Van Herpen, E.; Van Trijp, H. Causes \& Determinants of Consumers Food Waste: A Theoretical Framework. Report of the EU Project REFRESH Deliverable 1.4. 2017. Available online: https:/ / eu-refresh.org/causes-determinants-consumersfood-waste.html (accessed on 18 May 2020).

8. FAO. Global Food Losses and Food Waste-Extent, Causes and Prevention; FAO: Rome, Italy, 2011.

9. Stenmarck, Å.; Jensen, C.; Quested, T.; Moates, G.; Buksti, M.; Cseh, B.; Östergren, K. Estimates of European Food Waste Levels; FUSIONS, 2016. Available online: https:/ / www.eu-fusions.org/phocadownload/Publications/Estimates\%20of\%20European\% 20food\%20waste\%20levels.pdf (accessed on 4 May 2021).

10. Schanes, K.; Dobernig, K.; Gözet, B. Food waste matters-A systematic review of household food waste practices and their policy implications. J. Clean. Prod. 2018, 182, 978-991. [CrossRef]

11. Stangherlin, I.D.C.; de Barcellos, M.D. Drivers and barriers to food waste reduction. Br. Food J. 2018, 120, 2364-2387. [CrossRef]

12. Quested, T.E.; Marsh, E.; Stunell, D.; Parry, A.D. Spaghetti soup: The complex world of food waste behaviours. Resour. Conserv. Recycl. 2013, 79, 43-51. [CrossRef]

13. Van Geffen, L.; Van Herpen, E.; Van Trijp, H. Quantified Consumer Insights on Food Waste. Pan-European Research for Quantified Consumer Food Waste Understanding. Report of the EU Project REFRESH Deliverable 1.4. 2017. Available online: https:/ / eu-refresh.org/quantified-consumer-insights-food-waste (accessed on 8 June 2021).

14. Stefan, V.; Van Herpen, E.; Tudoran, A.A.; Lähteenmäki, L. Avoiding food waste by Romanian consumers: The importance of planning and shopping routines. Food Qual. Prefer. 2013, 28, 375-381. [CrossRef]

15. Diaz-Ruiz, R.; Costa-Font, M.; Gil, J.M. Moving ahead from food-related behaviours: An alternative approach to understand household food waste generation. J. Clean. Prod. 2018, 172, 1140-1151. [CrossRef]

16. Romani, S.; Grappi, S.; Bagozzi, R.P.; Barone, A.M. Domestic food practices: A study of food management behaviors and the role of food preparation planning in reducing waste. Appetite 2018, 121, 215-227. [CrossRef] [PubMed]

17. Van Dooren, C.; Janmaat, O.; Snoek, J.; Schrijnen, M. Measuring food waste in Dutch households: A synthesis of three studies. Waste Manag. 2019, 94, 153-164. [CrossRef]

18. Visschers, V.H.; Wickli, N.; Siegrist, M. Sorting out food waste behaviour: A survey on the motivators and barriers of self-reported amounts of food waste in households. J. Environ. Psychol. 2016, 45, 66-78. [CrossRef]

19. Schmidt, K.; Matthies, E. Where to start fighting the food waste problem? Identifying most promising entry points for intervention programs to reduce household food waste and overconsumption of food. Resour. Conserv. Recycl. 2018, 139, 1-14. [CrossRef]

20. Elimelech, E.; Ert, E.; Ayalon, O. Exploring the drivers behind self-reported and measured food wastage. Sustainability 2019, 11, 5677. [CrossRef]

21. Giordano, C.; Alboni, F.; Falasconi, L. Quantities, determinants, and awareness of households' food waste in Italy: A comparison between diary and questionnaires quantities. Sustainability 2019, 11, 3381. [CrossRef]

22. Evans, D. Blaming the consumer-once again: The social and material contexts of everyday food waste practices in some English households. Crit. Public Health 2011, 21, 429-440. [CrossRef]

23. Ganglbauer, E.; Fitzpatrick, G.; Comber, R. Negotiating food waste: Using a practice lens to inform design. ACM Trans. Comput. Hum. Interact. 2013, 20, 1-25. [CrossRef]

24. Radzymińska, M.; Jakubowska, D.; Staniewska, K. Consumer attitude and behaviour towards food waste. J. Agribus. Rural. Dev. 2016, 39, 175-181. [CrossRef] 
25. Koivupuro, H.K.; Hartikainen, H.; Silvennoinen, K.; Katajajuuri, J.M.; Heikintalo, N.; Reinikainen, A.; Jalkanen, L. Influence of socio-demographical, behavioural and attitudinal factors on the amount of avoidable food waste generated in Finnish households. Int. J. Consum. Stud. 2012, 36, 183-191. [CrossRef]

26. Parizeau, K.; von Massow, M.; Martin, R. Household-level dynamics of food waste production and related beliefs, attitudes, and behaviours in Guelph, Ontario. Waste Manag. 2015, 35, 207-217. [CrossRef]

27. Stancu, V.; Haugaard, P.; Lähteenmäki, L. Determinants of consumer food waste behaviour: Two routes to food waste. Appetite 2016, 96, 7-17. [CrossRef]

28. Falasconi, L.; Cicatiello, C.; Franco, S.; Segrè, A.; Setti, M.; Vittuari, M. Such a shame! A study on self-perception of household food waste. Sustainability 2019, 11, 270. [CrossRef]

29. Janssens, K.; Lambrechts, W.; Van Osch, A.; Semeijn, J. How Consumer Behavior in Daily Food Provisioning Affects Food Waste at Household Level in The Netherlands. Foods 2019, 8, 428. [CrossRef] [PubMed]

30. Giordano, C.; Alboni, F.; Cicatiello, C.; Falasconi, L. Do discounted food products end up in the bin? An investigation into the link between deal-prone shopping behaviour and quantities of household food waste. Int. J. Consum. Stud. 2019, 43, 199-209. [CrossRef]

31. Quested, T.E.; Parry, A.D.; Easteal, S.; Swannell, R. Food and drink waste from households in the UK. Nutr. Bull. 2011, 36, 460-467. [CrossRef]

32. Plumb, A.; Downing, P.; Parry, A. Consumer Attitudes to Food Waste and Food Packaging; WRAP: Banbury, UK, 2013.

33. Hebrok, M.; Boks, C. Household food waste: Drivers and potential intervention points for design-An extensive review. J. Clean. Prod. 2017, 151, 380-392. [CrossRef]

34. Jörissen, J.; Priefer, C.; Bräutigam, K.R. Food waste generation at household level: Results of a survey among employees of two European research centers in Italy and Germany. Sustainability 2015, 7, 2695-2715. [CrossRef]

35. Porpino, G.; Parente, J.; Wansink, B. Food waste paradox: Antecedents of food disposal in low income households. Int. J. Consum. Stud. 2015, 39, 619-629. [CrossRef]

36. Evans, D. Beyond the throwaway society: Ordinary domestic practice and a sociological approach to household food waste. Sociology 2012, 46, 41-56. [CrossRef]

37. Farr-Wharton, G.; Foth, M.; Choi, J.H.-J. Identifying factors that promote consumer behaviours causing expired domestic food waste. J. Consum. Behav. 2014, 13, 393-402. [CrossRef]

38. Graham-Rowe, E.; Jessop, D.C.; Sparks, P. Identifying motivations and barriers to minimising household food waste. Resour. Conserv. Recycl. 2014, 84, 15-23. [CrossRef]

39. Silvennoinen, K.; Katajajuuri, J.M.; Hartikainen, H.; Heikkilä, L.; Reinikainen, A. Food waste volume and composition in Finnish households. Br. Food J. 2014, 116, 1058-1068. [CrossRef]

40. Fanelli, R.M. Using causal maps to analyse the major root causes of household food waste: Results of a survey among people from Central and Southern Italy. Sustainability 2019, 11, 1183. [CrossRef]

41. Pearson, D.; Minehan, M.; Wakefield-Rann, R. Food waste in Australian households: Why does it occur? Aust. Pac. J. Reg. Food Stud. 2013, 3, 118-132.

42. Cox, J.; Downing, P. Food Behaviour Consumer Research: Quantitative Phase; WRAP: Banbury, UK, 2007.

43. Neff, R.A.; Spiker, M.L.; Truant, P.L. Wasted food: US consumers' reported awareness, attitudes, and behaviors. PLoS ONE 2015, 10, e0127881. [CrossRef]

44. Qi, D.; Roe, B.E. Household food waste: Multivariate regression and principal components analyses of awareness and attitudes among US consumers. PLoS ONE 2016, 11, e0159250. [CrossRef]

45. Djekic, I.; Miloradovic, Z.; Djekic, S.; Tomasevic, I. Household food waste in Serbia-Attitudes, quantities and global warming potential. J. Clean. Prod. 2019, 229, 44-52. [CrossRef]

46. McCarthy, B.; Liu, H.B. Food waste and the 'green' consumer. Australas. Mark. J. 2017, 25, 126-132. [CrossRef]

47. Exodus. We Don't Waste Food. A Household Survey. Final Report; WRAP: Banbury, UK, 2007.

48. Principato, L.; Secondi, L.; Pratesi, C.A. Reducing food waste: An investigation on the behaviour of Italian youths. Br. Food J. 2015, 117, 731-748. [CrossRef]

49. Barone, A.M.; Grappi, S.; Romani, S. "The road to food waste is paved with good intentions": When consumers' goals inhibit the minimization of household food waste. Resour. Conserv. Recycl. 2019, 149, 97-105. [CrossRef]

50. Abeliotis, K.; Lasaridi, K.; Chroni, C. Attitudes and behaviour of Greek households regarding food waste prevention. Waste Manag. Res. 2014, 32, 237-240. [CrossRef]

51. Van Boxstael, S.; Devlieghere, F.; Berkvens, D.; Vermeulen, A.; Uyttendaele, M. Understanding and attitude regarding the shelf life labels and dates on pre-packed food products by Belgian consumers. Food Control 2014, 37, 85-92. [CrossRef]

52. Ankiel, M.; Samotyja, U. The Role of Labels and Perceived Health Risk in Avoidable Food Wasting. Sustainability 2020, 12, 8725. [CrossRef]

53. Toma, L.; Font, M.C.; Thompson, B. Impact of consumers' understanding of date labelling on food waste behaviour. Oper. Res. Int. J. 2020, 20, 543-560. [CrossRef]

54. Cecere, G.; Mancinelli, S.; Mazzanti, M. Waste prevention and social preferences: The role of intrinsic and extrinsic motivations. Ecol. Econ. 2014, 107, 163-176. [CrossRef] 
55. Secondi, L.; Principato, L.; Laureti, T. Household food waste behaviour in EU-27 countries: A multilevel analysis. Food Policy 2015, 56, 25-40. [CrossRef]

56. Filipová, A.; Mokrejšová, V.; Šulc, Z.; Zeman, J. Characteristics of food-wasting consumers in the Czech Republic. Int. J. Consum. Stud. 2017, 41, 714-722. [CrossRef]

57. Ilakovac, B.; Voca, N.; Pezo, L.; Cerjak, M. Quantification and determination of household food waste and its relation to sociodemographic characteristics in Croatia. Waste Manag. 2020, 102, 231-240. [CrossRef] [PubMed]

58. Van der Werf, P.; Seabrook, J.A.; Gilliland, J.A. Food for naught: Using the theory of planned behaviour to better understand household food wasting behaviour. Can. Geogr. Le Géographe Can. 2019, 63, 478-493. [CrossRef]

59. Marangon, F.; Tempesta, T.; Troiano, S.; Vecchiato, D. Food waste, consumer attitudes and behaviour. A study in the North-Eastern part of Italy. Ital. Rev. Agric. Econ. 2014, 69, 201-209.

60. Grainger, M.J.; Aramyan, L.; Logatcheva, K.; Piras, S.; Righi, S.; Setti, M.; Vittuari, M.; Stewart, G.B. The use of systems models to identify food waste drivers. Glob. Food Secur. 2018, 16, 1-8. [CrossRef]

61. Grasso, A.C.; Olthof, M.R.; Boevé, A.J.; Van Dooren, C.; Lähteenmäki, L.; Brouwer, I.A. Socio-Demographic Predictors of Food Waste Behavior in Denmark and Spain. Sustainability 2019, 11, 3244. [CrossRef]

62. Hazuchova, N.; Antosova, I.; Stavkova, J. Food Wastage as a Display of Consumer Behaviour. J. Compet. 2020, 12, 51-66. [CrossRef]

63. Quested, T.; Luzecka, P. Household Food and Drink Waste: A People Focus; WRAP: Banbury, UK, $2014 ;$ p. 131.

64. Aschemann-Witzel, J.; De Hooge, I.; Amani, P.; Bech-Larsen, T.; Oostindjer, M. Consumer-related food waste: Causes and potential for action. Sustainability 2015, 7, 6457-6477. [CrossRef]

65. Lanfranchi, M.; Calabrò, G.; De Pascale, A.; Fazio, A.; Giannetto, C. Household food waste and eating behavior: Empirical survey. Br. Food J. 2016, 118, 3059-3072. [CrossRef]

66. Herzberg, R.; Schmidt, T.G.; Schneider, F. Characteristics and Determinants of Domestic Food Waste: A Representative Diary Study across Germany. Sustainability 2020, 12, 4702. [CrossRef]

67. Setti, M.; Falasconi, L.; Segrè, A.; Cusano, I.; Vittuari, M. Italian consumers' income and food waste behavior. Br. Food J. 2016, 118, 1731-1746. [CrossRef]

68. Hanssen, O.J.; Syversen, F.; Stø, E. Edible food waste from Norwegian households-Detailed food waste composition analysis among households in two different regions in Norway. Resour. Conserv. Recycl. 2016, 109, 146-154. [CrossRef]

69. Stancu, V.; Lähteenmäki, L. Consumer Food Waste in Denmark; DCA-Danish Centre for Food and Agriculture: Aarhus, Denmark, 2018.

70. Van Herpen, E.; Van der Lans, I.A.; Holthuysen, N.; Nijenhuis-de Vries, M.; Quested, T.E. Comparing wasted apples and oranges: An assessment of methods to measure household food waste. Waste Manag. 2019, 88, 71-84. [CrossRef]

71. Charbel, L.; Capone, R.; Grizi, L.; Debs, P.; Khalife, D.; Bilali, H.E. Preliminary insights on household food wastage in Lebanon. J. Food Secur. 2016, 4, 131-137. [CrossRef]

72. Quested, T.; Johnson, H. Household Food and Drink Waste in the UK; WRAP: Banbury, UK, 2009.

73. Abeliotis, K.; Lasaridi, K.; Chroni, C. Food waste prevention in Athens, Greece: The effect of family characteristics. Waste Manag. Res. 2016, 34, 1210-1216. [CrossRef] [PubMed]

74. Giordano, C.; Piras, S.; Boschini, M.; Falasconi, L. Are questionnaires a reliable method to measure food waste? A pilot study on Italian households. Br. Food J. 2018, 120, 2885-2897. [CrossRef]

75. Cicatiello, C.; Giordano, C. Measuring household food waste at national level: A systematic review on methods and results. $C A B$ Rev. Perspect. Agric. Veter Sci. Nutr. Nat. Resour. 2018, 13, 1-8. [CrossRef]

76. Delley, M.; Brunner, T.A. Household food waste quantification: Comparison of two methods. Br. Food J. 2018, 120, 1504-1515. [CrossRef]

77. Van der Werf, P.; Seabrook, J.A.; Gilliland, J.A. Food for thought: Comparing self-reported versus curbside measurements of household food wasting behavior and the predictive capacity of behavioral determinants. Waste Manag. 2020, 101, 18-27. [CrossRef] [PubMed]

78. Ammann, J.; Osterwalder, O.; Siegrist, M.; Hartmann, C.; Egolf, A. Comparison of two measures for assessing the volume of food waste in Swiss households. Resour. Conserv. Recycl. 2021, 166, 105295. [CrossRef] 